Article

\title{
Synthesis of Two Novel Azilsartan Cocrystals: Preparation, Physicochemical Characterization and Solubility Studies
}

\author{
Lei Gao and Xian-Rui Zhang * \\ School of Chemical Engineering and Resource Recycling, Wuzhou University, Wuzhou 543000, China; \\ gaolei_1008@163.com \\ * Correspondence: zhangyang159246@163.com; Tel.: +86-0774-5828709
}

Received: 1 August 2020; Accepted: 19 August 2020; Published: 21 August 2020

\begin{abstract}
Azilsartan is a novel angiotension II receptor blocker primarily used to treat high blood pressure. This is not a formulation-friendly molecule largely due to the inherent water-solubility pitfalls. In this paper, two novel cocrystals of azilsartan (AZ) were studied (AZ-BIP, AZ-BPE; BIP = 4,4'-bipyridine, $\mathrm{BPE}=$ trans-1,2-bis (4-pyridyl) ethylene) by solution crystallization. The structures of these two cocrystals were characterized by powder X-ray diffraction (PXRD), differential scanning calorimetry (DSC) and thermogravimetric analysis (TGA), including the single-crystal structure determination of AZ-BIP and AZ-BPE. In the cocrystals AZ-BIP (2:1) and AZ-BPE (2:1), two AZ molecules and one coformer formed a sandwich structure through $\mathrm{N}-\mathrm{H} \ldots \mathrm{N}$ interactions. These sandwich structures were extended into a one-dimensional structure through $\mathrm{O}-\mathrm{H} \ldots \mathrm{N}$ hydrogen bonds. The equilibrium solubility study demonstrated that the AZ-BIP and AZ-BPE cocrystals both showed higher solubility than azilsartan in water.
\end{abstract}

Keywords: azilsartan; 4,4'-bipyridine; cocrystal; solubility; structure; X-ray diffraction

\section{Introduction}

Among well-studied organic materials, drug cocrystals are considered an effective substitute for existing drug formulations. These can enhance the physical and chemical properties of the active pharmaceutical ingredient (APIs) without altering the covalent bond of the medication, and even affect the solubility, dissolution rate and bioavailability of the medication [1-8]. Without changing the covalent chemistry of drugs, drug salt is primarily used for improving the physical and chemical properties of drugs. Pharmaceutical cocrystals have been developed as an ideal optimization strategy only during the last 10 years. Three drug cocrystals have entered the market in the form of new chemical entities to date, including Entresto ${ }^{\circledR}[9]$ (a type of sacubitril-valsartan sodium cocrystal), Depakote ${ }^{\circledR}$, Depakine ${ }^{\circledR}[10]$ (a type of escitalopram oxalate citalopram-oxalic acid cocrystal) and the tramadol-celecoxib cocrystal [11]. The drug cocrystal market indicates that the reasonable design of new drug cocrystals by crystal engineering has favorable prospects for application.

Azilsartan is a novel angiotension II receptor blocker primarily used to treat high blood pressure mboxciteB12-crystals-903496,B13-crystals-903496. This is a Biopharmaceutics Classification System (BCS) Class II medication with poor aqueous solubility in water $(11.6 \mathrm{mg} / \mathrm{L})[14]$, whereas BIP and BPE that both contain a pyridine ring are identified as potential cocrystal coformers [15-22]. We reported three salt solvates of azilsartan (AZ) and 2-methylimidazole (included one hydrate, one acetone solvate and one tetrahydrofuran solvate) [14]. However, no azilsartan cocrystals with pyridine functional groups have been reported to date. In this paper, we report two novel cocrystals (namely AZ-BIP and AZ-BPE) of azilsartan with BIP and BPE. Although BIP and BPE are toxic compounds and consequently, 
these two cocrystal are useless for human application. Despite everything, supramolecular knowledge is always useful to the synthesis of other azilsartan cocrystals. Furthermore, this screening can guide the development of new cocrystals of azilsartan by unusual N-H ... N interaction instead of the general $\mathrm{O}-\mathrm{H} \ldots \mathrm{N}$ hydrogen bonds. The solubility and powder dissolution of the two cocrystals are also discussed further. The chemical structures of AZ, BIP and BPE molecules are shown in Scheme 1.<smiles>CCOc1nc2cccc(C(=O)O)c2n1Cc1ccc(-c2ccccc2-c2noc(=O)[nH]2)cc1</smiles>

Azilsartan (AZ)
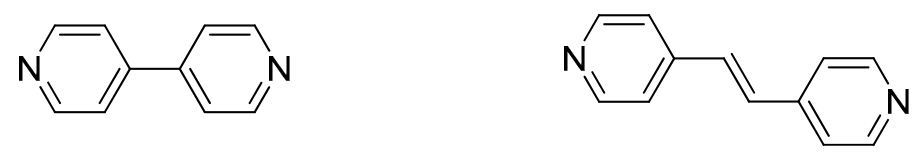

Scheme 1. Molecular structures of azilsartan, BIP and BPE.

\section{Materials and Methods}

\subsection{Materials and General Methods}

All chemicals and solvents were purchased from commercial sources and used without further purification. Differential Scanning Calorimetric (DSC) data were recorded using a Mettler-Toledo system at a heating rate of $10 \mathrm{~K} / \mathrm{min}$, and the runs were undertaken under the protection of nitrogen. Thermogravimetric analysis (TGA) was performed on a Perkin-Elmer TGA 4000 system (Shanghai, China). The heating rate was $10 \mathrm{~K} / \mathrm{min}$, and the runs were undertaken under the protection of nitrogen. Powder X-ray diffraction (PXRD) patterns were produced using a German Bruker corporation D8 ADVANCE system (Karlsruhe, Germany) with a $\mathrm{Cu} K \alpha$ radiation $(\lambda=1.5418 \AA, 40 \mathrm{kV}, 40 \mathrm{~mA})$, and the

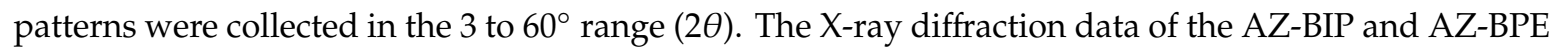
cocrystals were recorded on a Bruker Apex II CCD diffractometer (Karlsruhe, Germany) using Mo K $\alpha$ radiation $(\lambda=0.71073 \AA$ A $50 \mathrm{kV}, 30 \mathrm{~mA})$. The crystal structures of the AZ-BIP and AZ-BPE cocrystals were solved and refined using the SHELXL program [23,24]. The crystallographic parameters of synthesized cocrystals are listed in Table 1, and hydrogen bonds in Table 2. Docking simulations were performed using Molecular Operating Environment (MOE) software [25]. A flexible azilsartan molecule was docked into the angiotensin II type 1 receptor $\left(\mathrm{AT}_{1} \mathrm{R}\right)$ structure (http://www.pdb.org, PDB ID: 4ZUD) that had the binding site of azilsartan. The flexible AZ molecule was optimized using the MMFF94x force field, and partial charges were assigned to the atoms. The hydrogen bond networks of $\mathrm{AT}_{1} \mathrm{R}$ receptors were optimized by the Amber 99 force field. A Triangle Matcher was used as the docking placement method, and the MMFF94x force field was used to optimize the docking process. The top 30 poses were produced by the London dG scoring function, and the score of receptor-ligand complexes after forcefield refining was calculated by the Affinity dG scoring function [26]. 
Table 1. Crystallographic parameters for AZ-BIP (2:1) and AZ-BPE (2:1) cocrystals.

\begin{tabular}{|c|c|c|}
\hline & AZ-BIP & AZ-BPE \\
\hline Empirical formula & $\mathrm{C}_{30} \mathrm{H}_{24} \mathrm{~N}_{5} \mathrm{O}_{5}$ & $\mathrm{C}_{31} \mathrm{H}_{25} \mathrm{~N}_{5} \mathrm{O}_{5}$ \\
\hline Formula weight & 534.54 & 547.56 \\
\hline Wavelength (A) & 0.71073 & 0.71073 \\
\hline Crystal system & Monoclinic & Triclinic \\
\hline Space group & $C 2 / c$ & P-1 \\
\hline$a(\AA)$ & $28.9266(17)$ & $7.8907(4)$ \\
\hline$b(\AA)$ & $7.8175(5)$ & $12.6200(11)$ \\
\hline$c(\AA)$ & 24.9867(16) & $14.3849(10)$ \\
\hline$\alpha\left(^{\circ}\right)$ & 90 & $72.206(7)$ \\
\hline$\beta\left(^{\circ}\right)$ & $110.254(7)$ & $86.666(5)$ \\
\hline$\gamma\left({ }^{\circ}\right)$ & 90 & $82.996(5)$ \\
\hline $\mathrm{V}\left(\AA^{3}\right)$ & $5301.0(6)$ & $1353.42(17)$ \\
\hline Z & 8 & 2 \\
\hline$T / \mathrm{K}$ & $293(2)$ & $293(2)$ \\
\hline Density $\left(\mathrm{g} / \mathrm{cm}^{3}\right)$ & 1.340 & 1.344 \\
\hline$\mu\left(\mathrm{mm}^{-1}\right)$ & 0.094 & 0.093 \\
\hline Parameters & 379 & 379 \\
\hline$F(000)$ & 2232 & 572 \\
\hline Goodness-of-fit on F2 & 1.087 & 1.016 \\
\hline reflns. Collected & 4672 & 4758 \\
\hline unique reflns & 2950 & 3529 \\
\hline Final $R$ indices $[I>2 \sigma(I)]$ & $\begin{array}{c}\mathrm{R} 1=0.0706 \\
\omega \mathrm{R} 2=0.1703\end{array}$ & $\begin{array}{c}\mathrm{R} 1=0.0451 \\
\omega \mathrm{R} 2=0.0979\end{array}$ \\
\hline$\Delta \rho \max / \Delta \rho \min \left(\mathrm{e} \AA^{-3}\right)$ & $0.424 /-0.377$ & $0.346 /-0.294$ \\
\hline $\mathrm{CCDC}$ & $1,899,062$ & $1,899,063$ \\
\hline
\end{tabular}

Table 2. The Hydrogen bonding parameters of AZ-BIP (2:1) and AZ-BPE (2:1) cocrystals.

\begin{tabular}{ccccccc}
\hline & Interaction & $\mathbf{d}(\mathbf{D}-\mathbf{H})$ & $\mathbf{d}(\mathbf{H} \cdots \mathbf{A})$ & $\mathbf{d}(\mathbf{D} \cdots \mathbf{A})$ & $<$ (DHA) & Symmetry Code \\
\hline \multirow{2}{*}{ AZ-BIP } & N1-H1 $\cdots \mathrm{N} 5$ & 0.90 & 1.88 & $2.774(4)$ & 172 & $\mathrm{x}, \mathrm{y}-1, \mathrm{z}$ \\
& $\mathrm{O} 4-\mathrm{H} 2 \cdots \mathrm{N} 4$ & 0.91 & 1.75 & $2.650(4)$ & 171 & $\mathrm{x}, \mathrm{y}-1, \mathrm{z}$ \\
AZ-BPE & $\mathrm{N} 1-\mathrm{H} 1 \cdots \mathrm{N} 5$ & 0.96 & 1.78 & $2.741(3)$ & 175 & $\mathrm{x}, \mathrm{y}, \mathrm{z}$ \\
& $\mathrm{O} 5-\mathrm{H} 2 \cdots \mathrm{N} 4$ & 1.01 & 1.70 & $2.705(3)$ & 169 & $\mathrm{X}+1, \mathrm{y}, \mathrm{z}$ \\
\hline
\end{tabular}

\subsection{Synthesis of the AZ-BIP Cocrystal (2:1)}

The AZ-BIP cocrystal was produced by acetone assisted milling of a 2:1 molar ratio of AZ and BIP. A quantity of $40 \mathrm{mg}$ of the above samples was placed in $20 \mathrm{~mL}$ acetone solvent, and heat reflux for $2 \mathrm{~h}$. The solution was left at room temperature for slow evaporation. High-quality block crystals were generated after $5-7$ days.

\subsection{Synthesis of the AZ-BPE Cocrystal (2:1)}

The AZ-BPE cocrystal was prepared by acetone assisted milling of a 2:1 molar ratio of AZ and BPE. A quantity of $40 \mathrm{mg}$ of the above samples was placed in $10 \mathrm{~mL}$ methanol solvent, and heat reflux for $2 \mathrm{~h}$. The solution was left at room temperature for slow evaporation. High-quality block crystals were generated after 7-10 days.

\subsection{Solubility and Powder Dissolution Measurement}

Solubility was measured on a Shimadzu UV-2550 in water for $24 \mathrm{~h}$ at $37^{\circ} \mathrm{C}$. Three calibration curves of AZ, and the AZ-BIP and AZ-BPE cocrystals, were determined from aqueous solutions of known concentrations at $248 \mathrm{~nm}$. The powder dissolution studies were conducted suspending $50 \mathrm{mg}$ samples in $20 \mathrm{~mL}$ of water. These suspension liquids were stirred with magnetic force for $4 \mathrm{~h}$ at $37^{\circ} \mathrm{C}$. Then, specimens were drawn at a specified time $(5,10,15,20,25,30,45,60,90,120,180,240 \mathrm{~min})$ 
and filtered with a $0.22 \mu \mathrm{m}$ nylon filter. The concentration was measured within the range of its corresponding standard curve. Each experiment was repeated three times.

\section{Results and Discussion}

\subsection{Crystal Structure Analysis}

\subsubsection{AZ-BIP Cocrystal (2:1)}

The cocrystal of azilsartan with 4,4'-bipyridine (AZ-BIP) was solved in the monoclinic C2/c space group. The asymmetric unit contained one azilsartan molecule and half of a BIP molecules (Figure 1 and Supplementary Materials Figure S1). In the crystal structure of AZ-BIP cocrystal, two AZ molecules were connected to one BIP molecule through N1-H1 $\cdots \mathrm{N} 5\left(1.88 \AA, 172^{\circ}\right)$ interactions that were extended

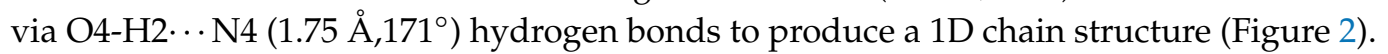

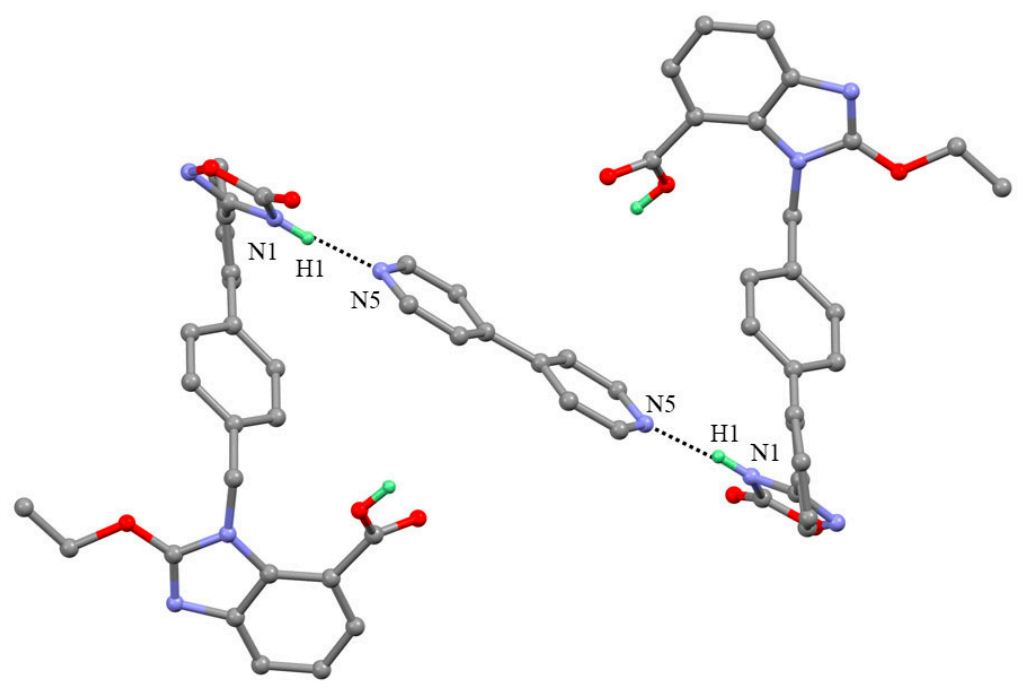

Figure 1. Two azilsartan (AZ) molecules were connected to one BIP molecule through $\mathrm{N} 1-\mathrm{H} 1 \cdots \mathrm{N} 5$ interactions.

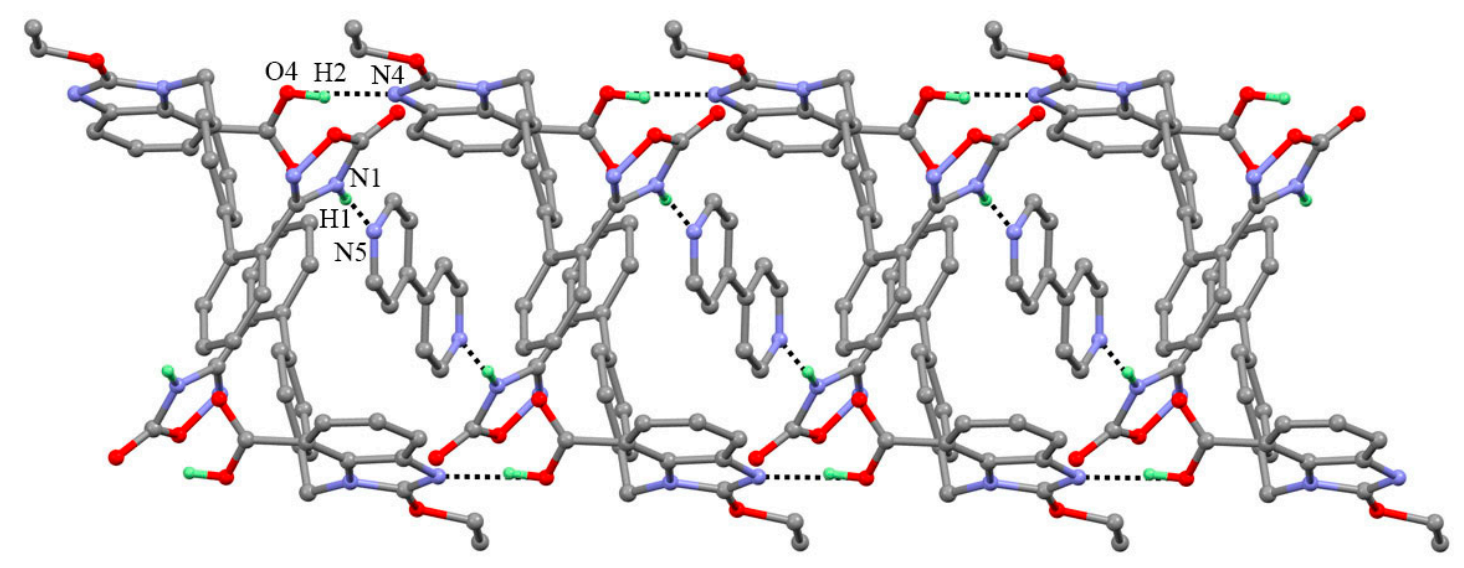

Figure 2. 1D chains were extended by $\mathrm{O} 4-\mathrm{H} 2 \cdots \mathrm{N} 4$ interactions.

\subsubsection{AZ-BPE Cocrystal (2:1)}

The cocrystal of azilsartan with BPE (AZ-BPE) was solved in the triclinic P-1 space group. The asymmetric unit contained one azilsartan molecule and half of a BPE molecule (Figure 3 and Figure S2 (Supplementary Materials)). In the crystal structure of the AZ-BPE cocrystal, two AZ molecules 
were connected to one BPE molecule through N1-H1 $\cdots \mathrm{N} 5\left(1.78 \AA, 175^{\circ}\right)$ interactions that were extended

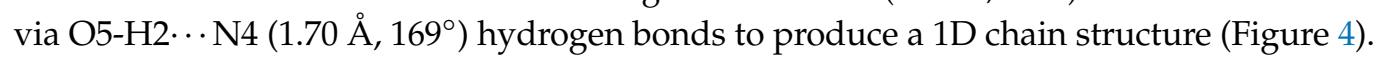

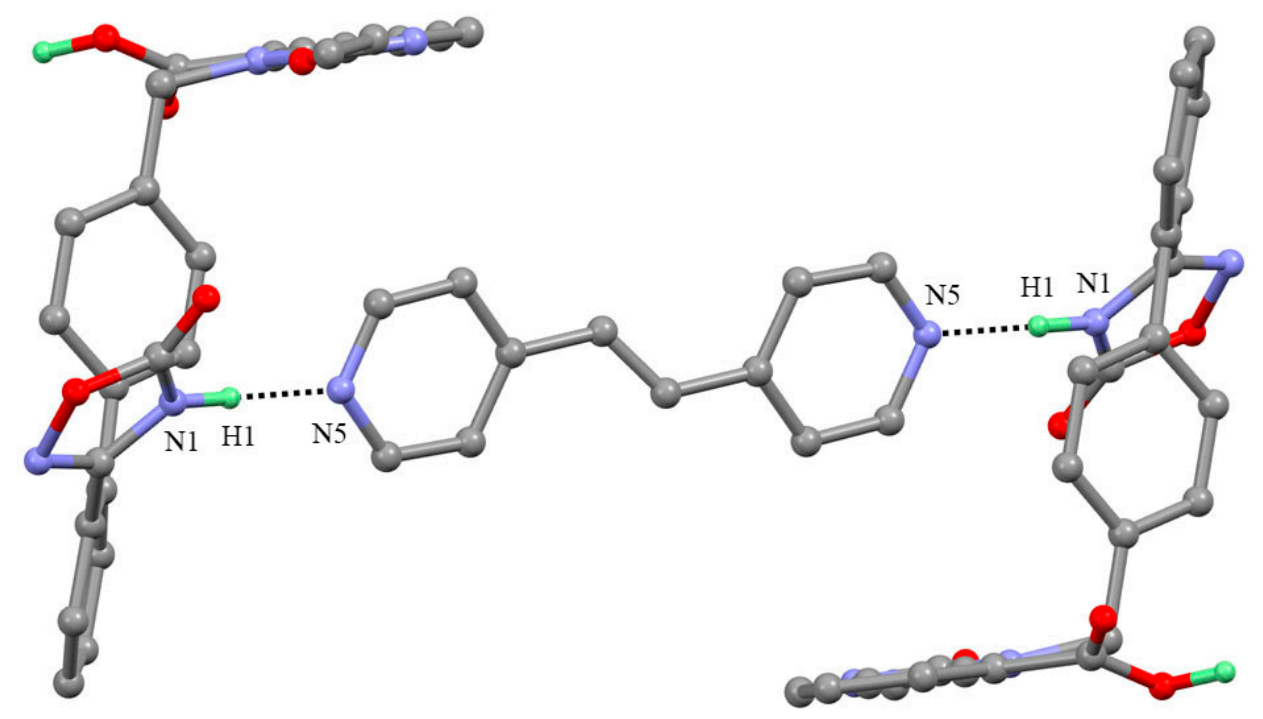

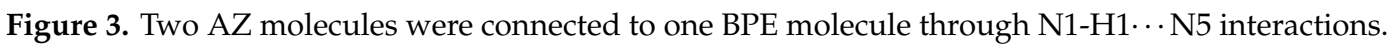

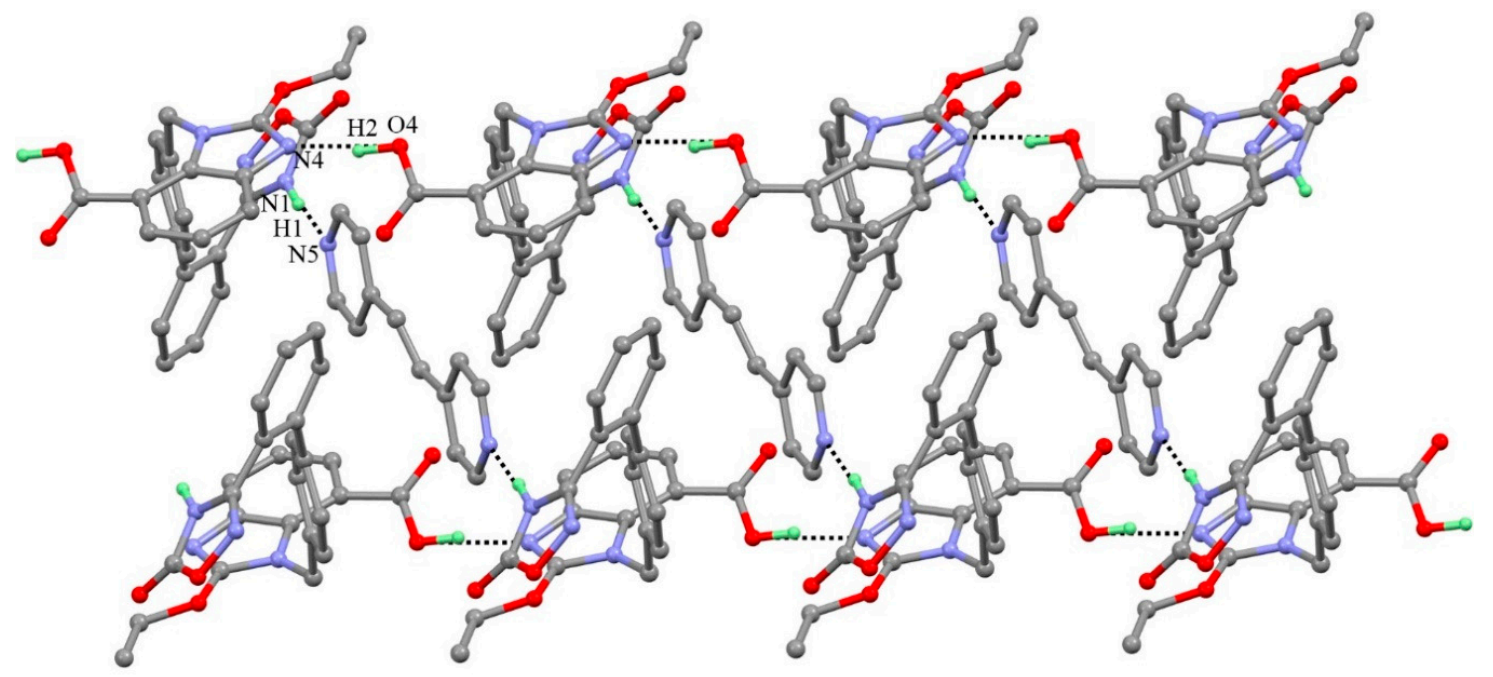

Figure 4. 1D chains were extended by $\mathrm{O} 5-\mathrm{H} 2 \cdots \mathrm{N} 4$ interactions.

The US-FDA suggested distinguishing between the formation of cocrystals and salts [27]. When the $\Delta \mathrm{pK}_{\mathrm{a}}$ of the two candidate compounds for cocrystal or salt is lower than 1, these two compounds are highly likely to form a cocrystal. When the $\Delta \mathrm{pK}_{\mathrm{a}}$ is higher than 3 , these two compounds are highly likely to form a salt. When the $\Delta \mathrm{pK}_{\mathrm{a}}$ is approximately 1 to 3 , there is no clear preference for cocrystals and salts [28]. As described in Table 3, the $\Delta \mathrm{pK}_{\mathrm{a}}$ of the parental compounds (BIP and BPE) of these two cocrystals was approximately 1 to 3. It was impossible to judge whether AZ-BIP and AZ-BPE were cocrystals or salts through $\triangle \mathrm{pK}$ a rules. However, Christer B suggested that the formation of cocrystals and salts can be distinguished from the C-O bonds lengths $(\AA)$ and $\mathrm{C}-\mathrm{N}-\mathrm{C}$ angles $\left(^{\circ}\right)[29]$. When the specific value of the $\mathrm{C}-\mathrm{O}$ bonds (long) to $\mathrm{C}-\mathrm{O}$ bonds (short) lengths was close to 1.027 (15), these two compounds were highly likely to form a salt, whereas the specific value was close to 1.081(12) for cocrystals. Obviously, the ratios were 1.112 and $1.086 \AA$ for AZ-BIP and AZ-BPE (Table 4), respectively. It can be concluded that both are cocrystals. Furthermore, the formation of cocrystals and salts could be distinguished from the endocyclic bond C-N-C angles for pyridine-based molecules. When the 
endocyclic bond C-N-C angles were less than $118.5^{\circ}$, these two compounds were highly likely to form a cocrystal. However, the C-N-C angles were over $120^{\circ}$ for salts. The endocyclic bond C-N-C angles were 114.2(4) and 116.2(2) ${ }^{\circ}$ for AZ-BIP and AZ-BPE (Table 4), respectively. Thus, AZ-BIP and AZ-BPE could be judged as cocrystals.

Table 3. $\mathrm{pK}_{\mathrm{a}}$ Values ${ }^{\alpha}$ of azilsartan and coformers used in this study.

\begin{tabular}{cccc}
\hline Compound & $\mathbf{p K}_{\mathbf{a}}$ & $\boldsymbol{\Delta} \mathbf{p K _ { \mathbf { a } }}$ & Cocrystal/Salt \\
\hline AZ & 3.51 & - & - \\
BIP & 5.25 & 1.74 & cocrystal \\
BPE & 4.99 & 1.48 & cocrystal
\end{tabular}

${ }^{\mathrm{a}} \mathrm{pK}_{\mathrm{a}}$ were calculated using Marvin 7.28.0, 2014, ChemAxon (http://www.chemaxon.com).

Table 4. Selected C-O bond lengths $(\AA)$ and C-N-C angles $\left(^{\circ}\right)$ for AZ and its cocrystals.

\begin{tabular}{ccccc}
\hline Bond & Bond & Distance & Angle & ${ }^{\circ}$ ) \\
\hline AZ-BIP & C25-O4 & $1.244(5)$ & C1-N1-C2 & $107.7(3)$ \\
& C25-O5 (average value) & $1.384(5)$ & C26-N5-C30 & $114.2(4)$ \\
AZ-BPE & C25-O4 & $1.204(2)$ & C1-N1-C2 & $108.03(19)$ \\
& C25-O5 & $1.308(2)$ & C26-N5-C30 & $116.2(2)$ \\
\hline
\end{tabular}

The crystal structure of the binding site of azilsartan, angiotensin II type 1 receptor $\left(\mathrm{AT}_{1} \mathrm{R}\right)$, has recently been described, which provides basic insights into the structure-functionality relationship [30]. Molecular docking simulation of azilsartan with the AngII-AT1 receptor was performed. The lowest total score ligand conformation (RMSD $<2.0)$ was selected as the optimal conformer (Figure S3 (Supplementary Materials)). The five planes (the benzimidazole group (A and B), biphenyl components (C and D), oxadiazole ring (E) and $\tau 1$ (C12-C15-N3) chain) of AZ had torsional flexibility (Figure 5a). In the following comparison, the C-planes of azilsartan were fixed and defined as a reference plane. Variable conformations of AZ in these 3 crystals (AZ, AZ-BIP and AZ-BPE) were compared with the optimal conformer and are shown in Figure $5 \mathrm{~b}$. Table 5 shows the torsion angle variation of $A Z$ molecules in these crystal structures and the optimal conformer. Results revealed that the conformer of the AZ molecule in the AZ-BPE crystal exhibited the closest structural similarity to the optimal conformer.

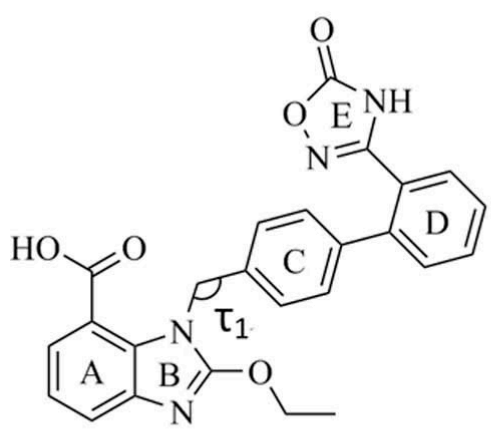

(a)

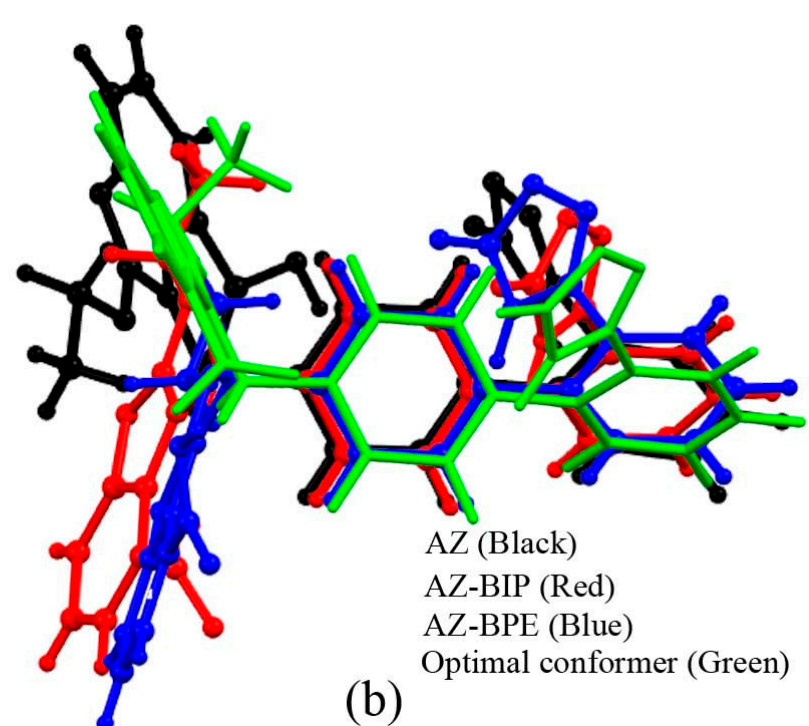

(b)

Figure 5. (a) Flexible twist angles and planes in Az. (b) Molecular stacking chart of the optimal conformer and three isomers of three crystals. 
Table 5. Torsion angle $\left(^{\circ}\right)$ variation in AZ crystal structures.

\begin{tabular}{cccccc}
\hline & A & B & D & E & $\boldsymbol{\tau}_{\mathbf{1}}$ \\
\hline optimal conformer & 78.8 & 79.7 & 61.7 & 122.9 & 0.9 \\
AZ & 114.1 & 111.6 & 60 & 103.3 & 167.0 \\
AZ-BIP & 75.3 & 76.3 & 51.8 & 56.7 & 60.4 \\
AZ-BPE & 85.9 & 86.9 & 48.0 & 47.2 & 23.3 \\
\hline
\end{tabular}

\subsection{PXRD Analysis}

The PXRD patterns of all cocrystals and coformers are shown in Figure 6. Characteristic peaks of AZ (Figure 6a) and BIP (Figure $6 \mathrm{~b}$ ) occurred at $2 \theta=9.14,12.67$ and $23.57^{\circ}$, and 10.46, 12.42, 19.50and $25.38^{\circ}$, respectively. The AZ-BIP cocrystal (Figure 6c) exhibited different peaks at $2 \theta$ values of 6.42 , $7.44,7.98,11.44,14.94,18.18,21.20,21.86,23.54$ and $28.58^{\circ}$, indicating the formation of new solid forms. The dominant characteristic peaks of the BPE (Figure 6d) and AZ-BPE (Figure 6e) cocrystal occurred at 13.94, 16.74, 17.36, 22.70, 24.14, 26.86 and $28.16^{\circ}$, and 7.98, 8.92, 10.94, 12.58, 18.40 and $23.94^{\circ}$, respectively. These results also confirmed the formation of the new solid forms.

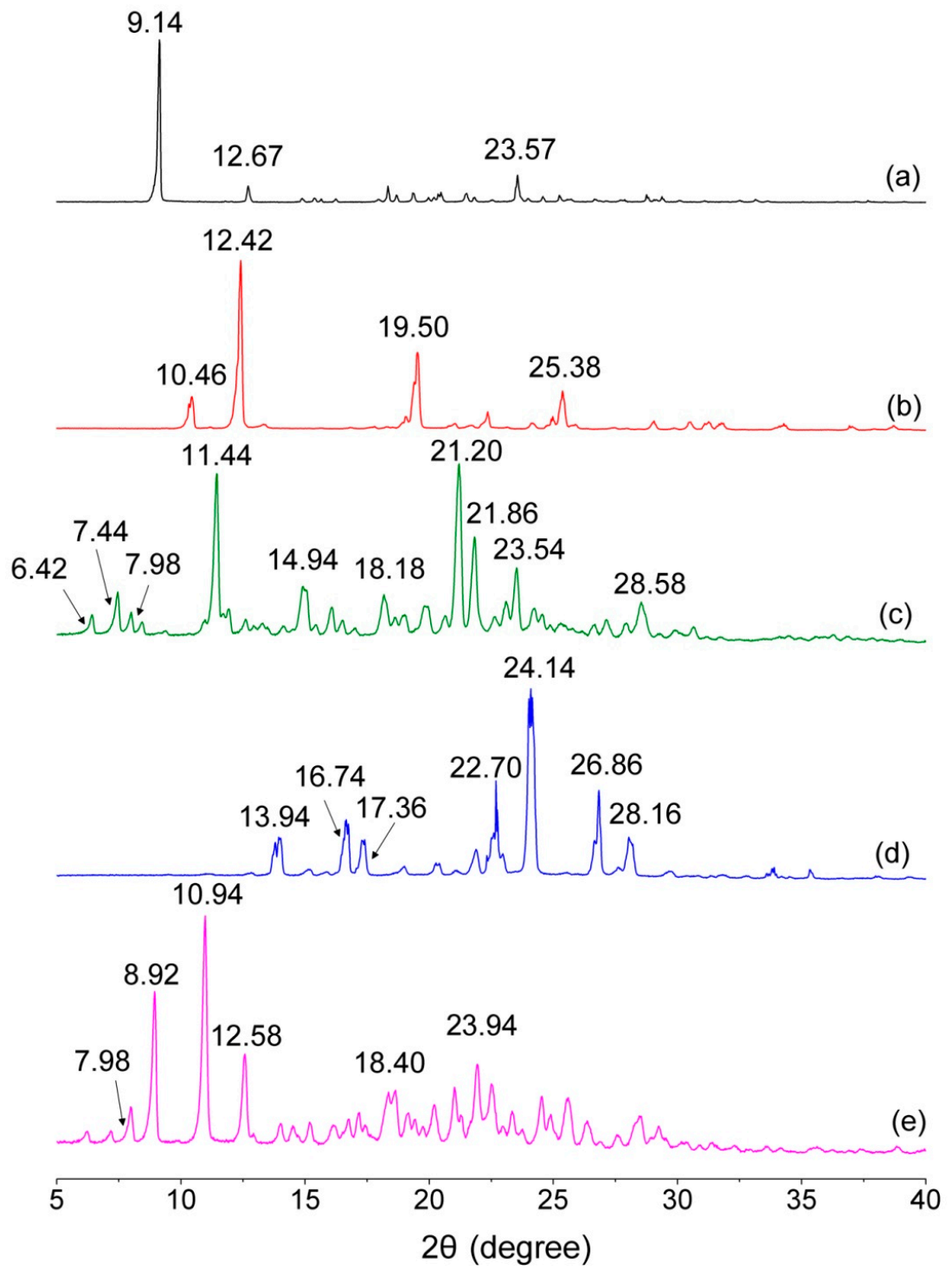

Figure 6. Powder X-ray diffraction (PXRD) patterns of (a) AZ, (b) BIP, (c) AZ-BIP, (d) BPE and (e) AZ-BPE. 


\subsection{DSC and TGA Analysis}

AZ, AZ-BIP and AZ-BPE cocrystals were studied by DSC and TGA under the protection of nitrogen. The DSC and TGA curves of the AZ, AZ-BIP and AZ-BPE cocrystals are displayed in Figures 7 and 8. The DSC thermograms of the AZ, BPE and AZ-BPE cocrystals showed a melting phenomenon at 206152 and $198{ }^{\circ} \mathrm{C}$, respectively. Subsequently, an exothermic peak attributed to decomposition endotherm occurred, and this was consistent with the TGA curves; while the DSC thermograms of the AZ-BIP cocrystal had a melting peak at $164{ }^{\circ} \mathrm{C}$. Two exothermic peaks were observed in the DSC, and these were attributable to secondary decomposition behavior.

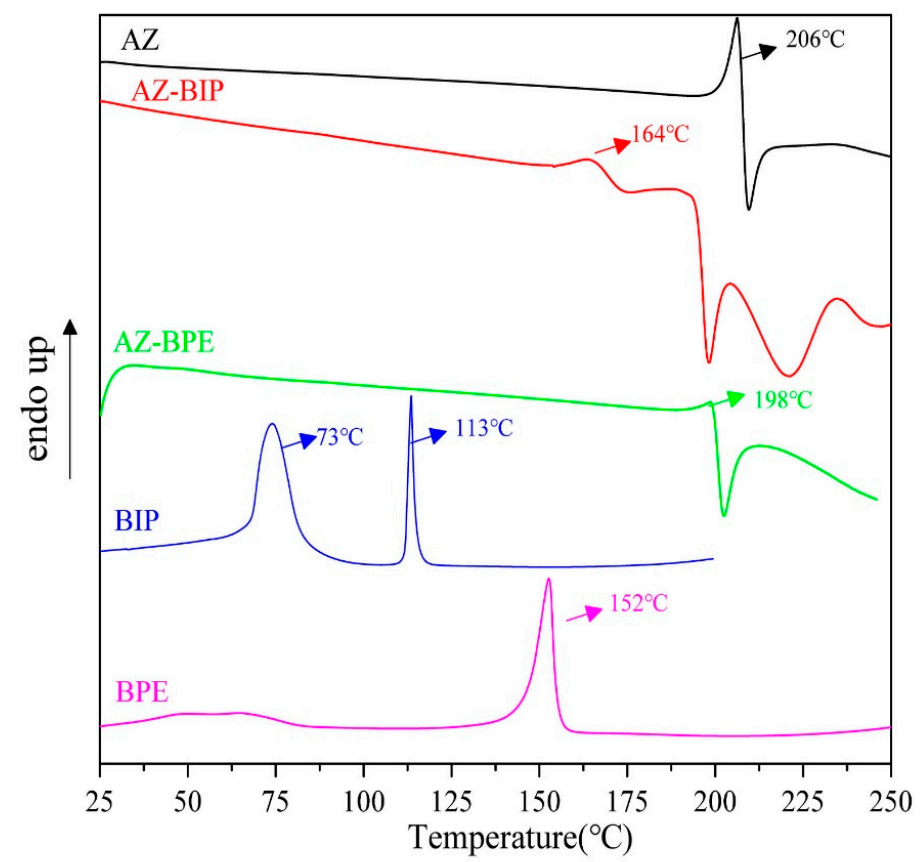

Figure 7. Differential scanning calorimetry (DSC) curves of AZ (black), AZ-BIP (red) and AZ-BPE (green) cocrystals recorded at $10 \mathrm{~K} / \mathrm{min}$ heating rate.

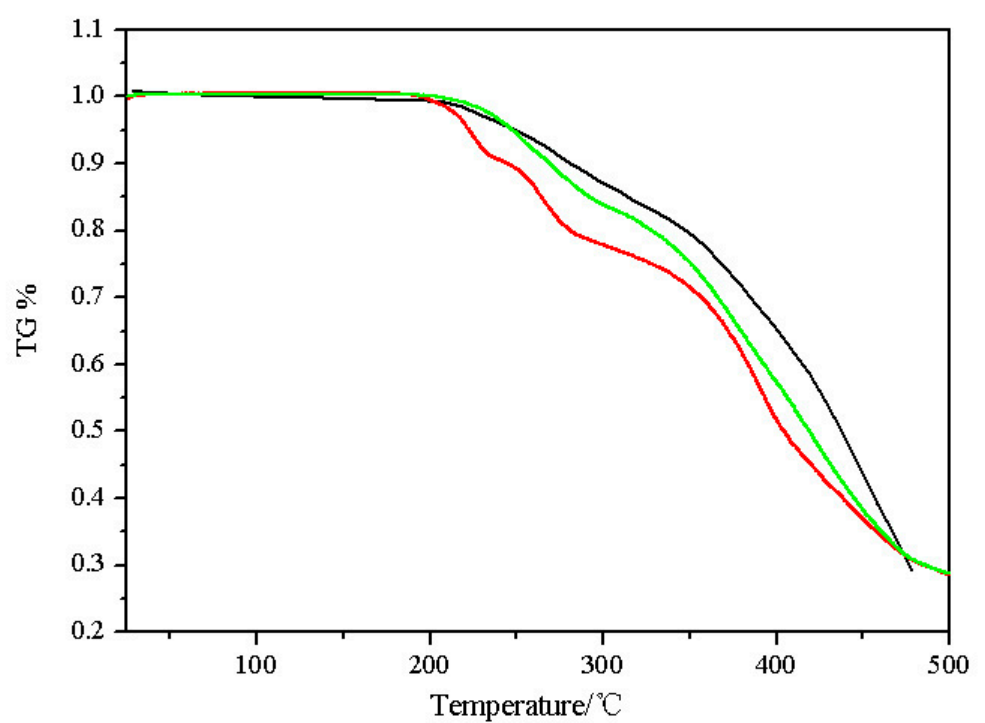

Figure 8. Thermogravimetric analysis (TGA) curves of AZ (black), AZ-BIP (red) and AZ-BPE (green) cocrystals recorded at $10 \mathrm{~K} / \mathrm{min}$ heating rate. 


\subsection{Solubility and Powder Dissolution Rate Analysis}

Solubility and powder dissolution results are shown in Figure 9 and Table 6. From Table 6, solubilities of the AZ-BIP and AZ-BPE cocrystals were both higher than that of azilsartan, indicating that the solubility of azilsartan can be increased by building a drug cocrystal. PXRD results of the residual samples after $24 \mathrm{~h}$ solubility experiments showed that the AZ-BIP and AZ-BPE cocrystals were stable (Figures S4 and S5 (Supplementary Materials)). The powder dissolution behavior for AZ and the AZ-BIP and AZ-BPE cocrystals in water at $37^{\circ} \mathrm{C}$ are shown in Figure 9. The AZ-BIP and AZ-BPE cocrystals both showed higher powder dissolution rates than AZ. However, the powder dissolution results showed that the AZ-BIP cocrystal took two hours to reach equilibrium, indicating that the process could take more time to approach dissolution equilibrium.

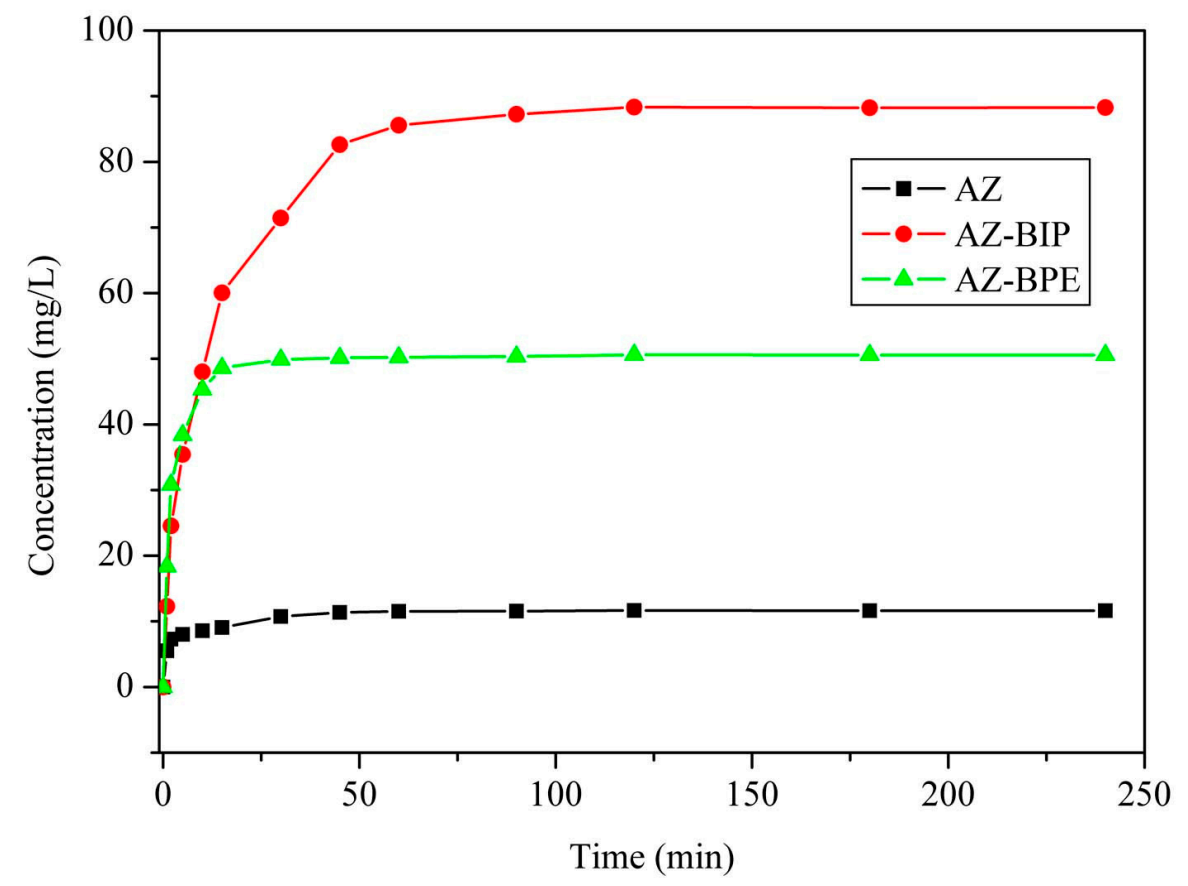

Figure 9. Powder dissolution profiles of AZ, AZ-BIP cocrystal and AZ-BPE cocrystal at different time points.

Table 6. Powder solubility comparisons of AZ and its cocrystals $(n=3)$.

\begin{tabular}{cc}
\hline Sample & Solubility of AZ and Its Cocrystals $(\mathbf{m g} / \mathrm{L})$ \\
\hline Azilsartan & 11.6 \\
AZ-BIP cocrystal & 88.3 \\
AZ-BPE cocrystal & 50.6 \\
\hline
\end{tabular}

\section{Conclusions}

Two novel cocrystals of an antihypertensive drug azilsartan were synthesized using the solution crystallization method. In the cocrystals AZ-BIP (2:1) and AZ-BPE (2:1), crystal structure analysis revealed that two AZ molecules and the coformer connected through $\mathrm{N}-\mathrm{H} \cdots \mathrm{N}$ H-bonds and formed a sandwich structure. Compared with AZ, the AZ-BIP and AZ-BPE cocrystals both showed improved solubility in water. After $24 \mathrm{~h}$ solubility experiments, PXRD results of the residual samples showed that the AZ-BIP and AZ-BPE cocrystals were stable. More profoundly, the powder dissolution profiles of these two cocrystals of azilsartan were studied. The two cocrystals of AZ showed better dissolution rates than that of pure AZ. The optimal conformer exhibited the best structural similarity to the AZ-BPE cocrystal via the angiotensin receptor $A_{1} R$. 
Supplementary Materials: The following are available online at http://www.ccdc.cam.ac.uk/data_request/cif, CCDC 1899062 and 1899063 contain the supplementary crystallographic data for this paper. These data can be obtained free of charge from The Cambridge Crystallographic Data Centre via.

Author Contributions: L.G. and X.-R.Z. conceived and designed the experiments; L.G. and X.-R.Z. performed the experiments and analyzed the data; X.-R.Z. supervised the work. All the authors have contributed to manuscript revision. All authors have read and agreed to the published version of the manuscript.

Funding: The work was supported by Guangxi Natural Science Foundation (Grant No.: 2018GXNSFBA281167) and the Basic Ability Promotion Project of Middle-aged and Young Teachers in Colleges and Universities in Guangxi (Grant No.: 2019KY0700 and 2020KY17020).

Conflicts of Interest: The authors declare no conflict of interest.

\section{References}

1. Gao, L.; Zhang, X.R.; Yang, S.P.; Liu, J.J.; Chen, C.J. Improved solubility of vortioxetine using C2-C4 straight-chain dicarboxylic acid salt hydrates. Crystals 2018, 8, 352. [CrossRef]

2. Gao, L.; Zhang, X.R.; Chen, Y.F.; Liao, Z.L.; Wang, Y.Q.; Zou, X.Y. A new febuxostat imidazolium salt hydrate: Synthesis, crystal structure, solubility, and dissolution study. J. Mol. Struct. 2019, 1176, 633-640. [CrossRef]

3. Mittapali, S.; Mannava, M.C.; Khandavilli, U.R.; Allu, S.; Nangia, A. Soluble salts and cocrystals of clotrimazole. Cryst. Growth Des. 2015, 15, 2493-2504. [CrossRef]

4. Yadav, J.A.; Khomane, K.S.; Modi, S.R.; Ugale, B.; Yadav, R.N.; Nagaraja, C.M.; Kumar, N.; Bansal, A.K. Correlating single crystal structure, nanomechanical, and bulk compaction behavior of febuxostat polymorphs. J. Mol. Pharm. 2017, 14, 866-874. [CrossRef] [PubMed]

5. Suresh, K.; Nangia, A. Lornoxicam salts: Crystal structures, conformations, and solubility. Cryst. Growth Des. 2014, 14, 2945-2953. [CrossRef]

6. Bolla, G.; Sanphui, P.; Nangia, A. Solubility advantage of tenoxicam phenolic cocrystals compared to salts. Cryst. Growth Des. 2013, 13, 1988-2003. [CrossRef]

7. Sanphui, P.; Bolla, G.; Nangia, A.; Chernyshev, V. A cemetacin cocrystals and salts: Structure solution from powder X-ray data and form selection of the piperazine salt. IUCrJ 2014, 1, 136-150. [CrossRef]

8. Maddileti, D.; Jayabun, S.K.; Nangia, A. Soluble cocrystals of the xanthine oxidase inhibitor febuxostat. Cryst. Growth Des. 2013, 13, 3188-3196. [CrossRef]

9. Fala, L. Entresto (Sacubitril/Valsartan): First-in-class angiotensin receptor neprilysin inhibitor FDA approved for patients with heart failure. Am. Health Drug Benef. 2015, 8, 330.

10. Scollo-Lavizzari, G.; Corbat, F.A. Clinical note on a new antiepileptic, 'Depakine ${ }^{\circledR}$ '. Eur. Neurol. 1970, 4, 312-317. [CrossRef]

11. Gascom, N.; Almansa, C.; Merlos, M.; Miguel Vela, J.; Encina, G.; Morte, A.; Smith, K.; Plata-Salaman, C. Co-crystals of tramadol-celecoxib: Preclinical and clinical evaluation of a novel analgesic. Expert Opin. Investig. Drugs 2019, 28, 399-409. [CrossRef] [PubMed]

12. Walsh, R.B.; Bradner, M.W.; Fleischman, S.; Morales, L.A.; Moulton, B.; Rodriguez-Hornedo, N.; Zaworotko, M.J. Crystal engineering of the composition of pharmaceutical phases. Chem. Commun. 2003, 2, 186-187. [CrossRef] [PubMed]

13. Baker, W.L.; White, W.B. Azilsartan medoxomil: A new angiotensin II receptor antagonist for treatment of hypertension. Ann. Pharmacother. 2011, 45, 1506-1515. [CrossRef] [PubMed]

14. French, C.J.; Zaman, A.T.; Sobel, B.E. The angiotensin receptor blocker, azilsartan medoxomil (TAK-491), suppresses vascular wall expression of plasminogen activator inhibitor typr-I protein protentially facilitating the stabilization of atherosclerotic plaques. J. Cardiovasc. Pharm. 2011, 58, 143-148. [CrossRef]

15. Zhang, X.R.; Zhang, L. Solvent effect on the self-assembly of salt solvates of an antihypertensive drug azilsartan and 2-methylimidazole. J. Mol. Pharm. 2017, 1137, 320-327. [CrossRef]

16. Su, X.; Zhang, Y.; Yin, H.; Liu, L.; Zhang, Y.; Wu, L.; Zhang, Q.; Wang, C.; Zhang, L.; Zhang, Y.; et al. Preparation of a 1:1.5 cocrystal of kaempferol with 4,4'-bipyridine based on analyzing intermolecular interaction of building units. J. Mol. Pharm. 2019, 1177, 107-116. [CrossRef]

17. Du, S.; Wang, Y.; Wu, S.; Yu, B.; Shi, P.; Bian, L.; Zhang, D.; Hou, J.; Wang, J.; Gong, J. Two novel cocrystals of lamotrigine with isomeric bipyridines and in situ monitoring of the cocrystallization. Eur. J. Pharm. Sci. 2017, 110, 19-25. [CrossRef] 
18. Srivastava, K.; Khan, E.; Shimpi, M.R.; Tandon, P.; Sinha, K.; Velaga, S.P. Molecular structure and hydrogen bond interactions of a paracetamol-4,4'-bipyridine cocrystal studied using a vibrational spectroscopic and quantum chemical approach. CrystEngComm 2018, 20, 213-222. [CrossRef]

19. Du, J.J.; Stanton, S.A.; Williams, P.A.; Ong, J.A.; Groundwater, P.W.; Overgaard, J.; Platts, J.A.; Hibbs, D.E. Using electron density to predict synthon formation in a 4-hydroxybenzoic acid: 4,4'-bipyridine cocrystal. Cryst. Growth Des. 2018, 18, 1786-1798. [CrossRef]

20. Du, J.; Lai, F.; Varadi, L.; Williams, P.; Groundwater, P.; Platts, J.A.; Hibbs, D.E.; Overgaard, J. Monoclinic paracetamol vs. paracetamol-4,4'-bipyridine co-crystal; What is the difference? A charge density study. Crystals 2018, 8, 46. [CrossRef]

21. Nath, N.K.; Hazarika, M.; Gupta, P.; Ray, N.R.; Paul, A.K.; Nauha, E. Plastically bendable crystals of probenecid and its cocrystal with 4,4'-bipyridine. J. Mol. Struct. 2018, 1160, 20-25. [CrossRef]

22. Zhang, Y.N.; Yin, H.M.; Zhang, Y.; Zhang, D.J.; Su, X.; Kuang, H.X. Cocrystals of kaempferol, quercetin and myricetin with 4,4'-bipyridine: Crystal structures, analyses of intermolecular interactions and antibacterial properties. J. Mol. Struct. 2017, 1130, 199-207. [CrossRef]

23. Sheldrick, G.M. SHELXL-97; PC version; University of Göttingen: Göttingen, Germany, 1997.

24. Sheldrick, G.M. SHELXTL; version 5.1; Bruker Analytical X-ray Instruments Inc.: Madison, WI, USA, 1998.

25. Molecular Operating Environment (MOE); 2010.10; ChemicalComputing Group Inc.: Montreal, QC, Canada, 2012. Available online: https://www.chemcomp.com/ (accessed on 20 August 2020).

26. Corbeil, C.R.; Williams, C.I.; Labute, P. Variability in docking success rates due to dataset preparation. J. Comput. Aided Mol. Des. 2012, 26, 775-786. [CrossRef]

27. Guidelines for Industry: Regulatory Classification of Pharmaceutical Co-Crystals. U.S. Food and Drug Administration. Available online: http://www.fda.gov/downloads/Drugs/Guidances/UCM281764.pdf/ (accessed on 16 February 2014).

28. Cruz-Cabeza, A. Acid-base crystalline complexes and the pKa rule. CrystEngComm 2012, 14, $6362-6365$. [CrossRef]

29. Aakeroy, C.B.; Fasulo, M.E.; Desper, J. Cocrystals or salts: Does it really matter? Mol. Pharm. 2007, 4, 317-322. [CrossRef] [PubMed]

30. Zhang, H.; Unal, H.; Gati, C.; Han, G.W.; Liu, W.; Zatsepin, N.A.; James, D.; Wang, D.; Xu, Q.; White, T.A.; et al. Structure of the Angiotensin receptor revealed by serial femtosecond crystallography. Cell 2015, 161, 833-844. [CrossRef] [PubMed] 